\section{Principais fatores associados à ocorrência de acidentes de trânsito na BR 163, Mato Grosso, Brasil, 2004}

\author{
Main factors associated with motor vehicle \\ accidents on Federal Highway 163, Mato Grosso \\ State, Brazil, 2004
}

\author{
1 Instituto de Saúde Coletiva, \\ Universidade Federal de \\ Mato Grosso, Cuiabá, Brasil. \\ 2 Instituto de Ciências Exatas \\ e da Terra, Universidade \\ Federal de Mato Grosso, \\ Cuiabá, Brasil. \\ Correspondência \\ L. V. C. Almeida \\ Núcleo de Estudos \\ Ambientais e Saúde do \\ Trabalhador, Instituto de \\ Saúde Coletiva, Universidade \\ Federal de Mato Grosso. \\ Av. Fernando Correa da Costa \\ s/n, Campos Universitário, \\ Cuiabá, $M T$ \\ 78060-900, Brasil \\ ideiaoriginal@hotmail.com
}

\section{Abstract}

Transportation is essential to the economic development of Mato Grosso State, Brazil, and Federal Highway 163 is the main route for marketing regional agricultural produce. One unfortunate consequence of this activity is the occurrence of motor vehicle accidents. With the aim of analyzing and categorizing the main factors associated with motor vehicle accidents on this highway, the current study used data from the Mato Grosso State Division of the Brazilian Federal Highway Patrol for the year 2004. Factors significantly associated with accidents involving casualties were: substandard paving (OR = 1.89; CI: 1.32-2.70); front-end collisions $(O R=14.14 ; C I: 8.96-22.32)$; and running over pedestrians $(O R=35.95$; CI: 8.10-159.52. Contributing factors included highway maintenance problems $(\mathrm{OR}=4.35$; CI: 1.949.75) and disobeying traffic signs (OR = 5.69; CI: 2.01-16.12). In conclusion, reduction of motor vehicle accidents on this highway requires comprehensive intervention rather than targeting measures only to drivers or highway patrol personnel, but considering regional issues and their economic, social, and cultural dimensions.

Traffic Accidents; Roads; Motor Vehicles
Lívia Victório de Carvalho Almeida 1

Marta Gislene Pignatti 1

Mariano Martinez Espinosa 2

\section{Introdução}

O acidente de trânsito nas rodovias é um problema grave em todo o mundo. Estima-se que em 2002, quase 1,2 milhão morreram em conseqüência de acidentes de trânsito nas rodovias, representando mundialmente uma média de 3.242 mortes por dia e de 20 milhões a 50 milhões de feridos por ano. No ano de 2004, ocorreu no Brasil uma média de 308 acidentes por dia (aproximadamente 13 acidentes por hora) somente nas rodovias federais, matando especialmente homens na faixa etária de 15 a 44 anos. Entre as mulheres da mesma faixa etária é considerado a quinta causa de morte 1 .

No Brasil, o transporte rodoviário vem sendo colocado como principal articulador do circuito econômico de distribuição de mercadorias. De acordo com dados da Confederação Nacional de Transportes (CNT), referentes ao ano de 2003, o modal rodoviário concentra cerca de $65 \%$ do total da carga transportada 2 . Para o Estado de Mato Grosso, sendo sua malha ferroviária incipiente e devido a sua localização geográfica e logística de distribuição que privilegia a malha rodoviária, esta é praticamente a via única para o escoamento dos crescentes números de sua produção agropecuária.

Respondendo à necessidade da própria cadeia produtiva e do desenvolvimento regional, os produtos deste estado precisam ser transportados para serem transformados em subprodutos, 
ou comercializados, sendo a rodovia BR 163 eixo de expansão do desenvolvimento para o norte do estado e área de influência.

A atividade de transporte leva a um grande número de acidentes que impactam os indicadores de morbidade e mortalidade. No caso particular da BR 163, pela própria característica do transporte de cargas agropecuárias, estima-se que muitos trabalhadores da área do transporte sejam as principais vítimas dos acidentes.

Os acidentes de trânsito têm sido estudados em diferentes espaços, temporalidades e sob diferentes perspectivas $3,4,5,6,7$. Os autores concordam em considerar o acidente e suas conseqüências como um problema de Saúde Pública prevenível, uma vez que são decorrentes de deficiências das vias, dos veículos e das falhas humanas 8

No Estado de Mato Grosso, no ano de 2004, de acordo com dados do Sistema Informação de Mortalidade - SIM, as causas externas representaram a segunda maior causa de morte, perdendo apenas para as doenças do aparelho circulatório. Dentre as causas externas aos acidentes de trânsito coube a fatia de quase $35 \%$ do total (Departamento de Informática do SUS. Dados do SUS. http:/ / www.datasus.gov.br, acessado em Ago/2007).

A maior parte dos estudos sobre acidentes é feito por intermédio dos sistemas de informação em saúde, que são localizados segundo os limites municipais, estaduais, regionais ou mesmo nacionais, referindo-se ao local de ocorrência ou residência do óbito ou internação. Dessa forma, somente os acidentes que envolveram indivíduos que procuraram (voluntária ou involuntariamente) os serviços médicos são inseridos nas estatísticas.

No entanto, em alguns casos é preciso localizar os acidentes fora desses limites, por exemplo, no caso de acidentes em rodovias, que perpassam diferentes municípios. Nestes casos os dados disponíveis nos sistemas de informação de saúde são pouco eficazes, já que não possibilitam um estudo que os localize neste espaço. É, portanto, necessário recorrer a outras fontes de dados, a saber: as Polícias Rodoviárias - Estadual ou Federal - dependendo da jurisdição da rodovia. Os dados de cada órgão são coletados de forma a possibilitar conhecer as condições (do veículo, do condutor, e do local do acidente) que co-existiam no momento do acidente, o que pode nos revelar os fatores associados para ocorrência deles. Outra vantagem é a possibilidade de captar o acidente em si e não suas conseqüências (óbito ou internação)

Com o objetivo de categorizar e analisar os principais fatores presentes na ocorrência dos acidentes na rodovia BR 163, foram utilizados dados da Superintendência Regional de Polícia Rodoviária Federal de Mato Grosso referente ao ano de 2004 com vistas a subsidiar medidas de controle e mitigação dos mesmos.

\section{Metodologia}

Trata-se de um estudo de corte transversal em que foi selecionado o ano de 2004 para a realização das análises dos acidentes ocorridos na rodovia BR 163, Estado do Mato Grosso. O ano de 2004 foi escolhido por se tratar do ano em que ocorreu o maior número de óbitos relacionados a causas externas no estado, sendo o acidente de transporte responsável pela maior parte dos óbitos.

Sendo a BR 163 uma rodovia que corta transversalmente todo o estado, o trecho a ser analisado localiza-se entre os municípios de Itiquira e Guarantã do Norte. Logo, para efeitos deste estudo, foram considerados como BR 163 os trechos que incluem os quilômetros 0 ao 120 e 507 a 1.123 da BR 163 e também os quilômetros 200 ao 587 da BR 364 - trecho onde ocorre a sobreposição destas rodovias.

Conforme informações do Departamento de Infra-estrutura de Trânsito (DNIT), esta rodovia não se encontra pavimentada no trecho entre os $\mathrm{km} 1067,5$ ao 1121,2 , ou seja, nas proximidades da divisa com o Estado do Pará. Além disso, a grande maioria dos trechos é classificada como em condição regular 9

As fontes utilizadas foram os dados secundários sobre acidentes ocorridos na BR 163 no ano de 2004, coletados mediante o acesso às informações da Superintendência Regional de Polícia Rodoviária Federal após prévio consentimento. Tais dados se baseiam nos Boletins de ocorrência preenchidos pelos policiais rodoviários federais após a ocorrência de um acidente. Um dos limites do dado refere-se justamente à dificuldade de reclassificação do acidente por falta de um sistema adequado de contra-referência, de modo que um acidente primeiramente classificado como "com feridos" deveria ser reclassificado como "com mortos", se até num prazo de trinta dias o óbito ocorrer. Por isso optou-se por unir a categoria "com feridos" e "com óbitos" e formar a categoria "com vítimas". As informações foram disponibilizadas em planilhas dinâmicas do Microsoft Excel. Em seguida, a partir do trecho de ocorrência do acidente, foram selecionados os acidentes que ocorreram na BR 163 - Mato Grosso no período de 2004 - e aqueles ocorridos no trecho da sobreposição (BR 163 e BR 364), que também foram considerados como BR 163. 
Desenvolveu-se uma análise categórica considerando as seguintes variáveis: (a) tipo de veículo (bicicleta, motoneta, motocicleta, triciclo, automóvel, caminhonete, camioneta, microônibus, ônibus, caminhão, reboque, semi-reboque, trator, cavalo mecânico, tração animal, outros); (b) tipo de carga (sem carga, não aplicável, carga viva, não classificado, produtos perigosos, eletroeletrônico, alimentícios, outros); (c) fatores contribuintes à ocorrência do acidente (buraco na pista, defeito mecânico, desobediência à sinalização, dormindo, falta de atenção, ultrapassagem indevida, velocidade incompatível, outras causas); (d) classificação do acidente (com vítima, sem vítima); (e) via com pista (simples, dupla, múltipla); (f) condição do rolamento da pista (boa, regular, má e ruim); (g) traçado da pista (cruzamento, curva, tangente); (h) estado dos pneus (bom, regular, liso, ignorado); e (i) tempo de habilitação do motorista (menos de 1 ano, 14 anos, 5-9 anos, 10-14 anos, 15-19 anos, 20-24 anos, 25-29 anos, mais de 29 anos, inabilitado, ignorado, não exigível).

Desenvolveu-se uma análise descritiva dos acidentes e posteriormente análise de testes de qui-quadrado, destacando os fatores associados à maior chance de ocorrência de acidentes com maior gravidade até um nível de significância $\alpha \leq 0,05$. Foram considerados como acidentes de maior gravidade aqueles classificados como "com vítimas". Para o processamento estatístico dos dados, utilizou-se o pacote estatístico Minitab versão 14 (Minitab Inc., State College, Estados Unidos).

\section{Aspectos éticos}

A pesquisa foi aprovada pelo Comitê de Ética e Pesquisa envolvendo seres humanos do Hospital Universitário Júlio Müller sob o número de protocolo 343/CEP-HUJM/07. Foram respeitadas as normas regulamentadoras expressas na Resolução no. 196/96 do Conselho Nacional de Saúde.

\section{Resultados e discussão}

\section{Caracterização geral dos acidentes}

A média mensal de acidentes na BR 163 para o ano de 2004 foi de 156,75 acidentes/mês. Os meses de fevereiro, junho e outubro destacaram-se pelo número de acidentes ocorridos (193, $186 \mathrm{e}$ 186, respectivamente). Por outro lado, o mês de novembro foi o mês de menor ocorrência (114 acidentes).

Houve 3.317 veículos envolvidos nos 1.881 acidentes, vale dizer, uma média de 1,76 veículo/ acidente. A maioria dos acidentes $(55,8 \%)$ envolveu dois veículos, 34,9\% envolveram apenas um veículo e 9,3\% envolveram três ou mais veículos.

A grande maioria $(90,7 \%)$ dos condutores envolvidos em acidentes foi do sexo masculino, sendo somente $2,2 \%$ do sexo feminino e $7,2 \%$ de sexo ignorado. Acredita-se que a própria característica da BR 163, que remete ao transporte de mercadorias e pessoas, atividades que em geral são executadas por condutores do sexo masculino, poderia ajudar a explicar esta tão expressiva freqüência de condutores deste sexo envolvidos em acidentes.

Sexta-feira, quinta-feira e sábado foram os dias com maior ocorrência de acidentes (16,3\%, $15,8 \%$ e 15,6\%, respectivamente). Já no domingo e na segunda-feira, observou-se o menor percentual de acidentes ocorridos neste período (12,6\% para cada um). Essa distribuição pode ter relação com a própria logística de transporte e distribuição de mercadorias, pois boa parte dos condutores de veículos de transporte de cargas trabalha por produtividade. Assim, nas proximidades do final de semana (quinta e sexta) é possível que o motorista tenha pressa em carregar e/ou descarregar o veículo, quer seja para seguir viagem e conseguir maior produtividade, quer seja para passar o final de semana em casa com os familiares, o que pode resultar num número aumentado de acidentes nestes dias.

Observando a distribuição dos acidentes segundo traçado da pista, tem-se que a maior parte dos acidentes $(82,9 \%)$ ocorreu na pista com traçado tangente (ou seja, na chamada "reta"), $15,5 \%$ na curva e $1,6 \%$ no cruzamento. Isso pode ser explicado pelo fato de a BR 163 possuir boa parte do seu traçado do tipo tangente. Além disso, é preciso ter em conta que, ao contrário da curva, local normalmente vinculado a maior perigo, na "reta" existe uma tendência de "sensação de segurança" fato que pode favorecer o acometimento de abusos, tais como excesso de velocidade, ultrapassagens perigosas etc.

A maioria dos acidentes (56,3\%) ocorreu durante pleno dia, seguido do período da noite $(29,5 \%)$, ao anoitecer $(7,3 \%)$ e ao amanhecer $(6,9 \%)$.

Analisando os acidentes segundo condições do tempo, verificou-se que o maior número deles (63,3\%) aconteceu em condições do tempo consideradas boas, $16,5 \%$ com presença de chuva, $10,8 \%$ em tempo nublado e $1,4 \%$ em condições de neblina.

Os acidentes classificados como "saída de pista" foram os mais freqüentes, respondendo com mais de um quarto do total de acidentes $(26,3 \%)$. Em seguida aparecem os acidentes do tipo colisão traseira $(23,1 \%)$, colisão lateral $(18,9 \%)$, colisão 
frontal $(7,5 \%)$, tombamento $(7 \%)$. Os acidentes do tipo engavetamento foram os menos freqüentemente observados nesta rodovia, respondendo por menos de $1 \%$ do total de acidentes $(0,6 \%)$.

O fator contribuinte para a ocorrência de acidentes na BR 163 não foi especificado em 41,9\% do total de acidentes, sendo incluído na categoria “outras causas". Dentre as causas especificadas, a falta de atenção foi a principal $(16,4 \%)$, seguido pela presença de buraco na pista $(13,1 \%)$ e distância do segmento (8,0\%).

Mais de 90\% dos acidentes ocorridos nesta rodovia $(92,9 \%)$ foram na via do tipo simples, que é exatamente o tipo de via da pista mais comum nesta rodovia, $6,8 \%$ na via da pista dupla e $0,3 \%$ na múltipla.

A maior parte dos acidentes ocorreu em pistas com boas condições de rolamento $(60,2 \%)$, sendo os restantes $38,8 \%$ distribuídos entre as condições de rolamento regular (10,8\%), má $(4,6 \%)$, e ruim $(24,4 \%)$, ou seja, em condições de rolamento não adequado.

Quase 61\% dos acidentes ocorreram em localidades onde a sinalização horizontal foi considerada boa. Os demais acidentes ocorreram em trechos onde a sinalização foi considerada irregular (8,8\%), em más condições $(14,5 \%)$ ou ainda onde não havia tal sinalização (16\%). A sinalização horizontal visa transmitir informações ou advertências aos motoristas, sendo uma das suas principais vantagens a possibilidade de fazê-lo sem que os condutores desviem sua atenção da rodovia. Para o tráfego noturno, uma boa sinalização horizontal é indispensável porque, em algumas ocasiões, torna-se difícil visualizar o próprio corpo estradal 10. Esse tipo de sinalização pode ser comprometido por condições climáticas e desgaste provocado pelo tráfego.

Pouco mais da metade (50,9\%) dos acidentes da BR 163 ocorreram em situação de boa sinalização vertical, os restantes $49,1 \%$ aconteceram em situações em que era inadequada, isto é, em trechos cuja condição era irregular (11,8\%), em más condições (12\%) ou mesmo onde não havia tal sinalização (25,3\%). É válido salientar que este tipo de sinalização tem como finalidade a regulamentação do uso da via, a advertência para situações potencialmente perigosas ou problemáticas do ponto de vista operacional, o fornecimento de indicações, orientações e informações aos usuários, além do fornecimento de mensagens educativas 10

Ressalta-se que é preciso considerar que a intervenção nestes fatores (sinalização horizontal e vertical) possivelmente é uma estratégia passível de favorecer a diminuição na ocorrência de acidentes.
A maioria (50,08\%) dos acidentes ocorridos na BR 163 no ano de 2004 envolveu pelo menos um veículo do tipo "cavalo mecânico", as chamadas carretas com engate para reboque e/ou semi-reboque, em que estiveram envolvidos 1.239 veículos deste tipo (Tabela 1). Também foram muito comuns nesta rodovia os acidentes que envolveram automóveis $(29,56 \%)$ e caminhões (25,73\%), estando envolvidos 614 automóveis e 524 caminhões. Isso possivelmente reflete a própria característica de tráfego da rodovia a qual apresenta intensa circulação de veículos destes tipos dada às necessidades regionais.

A Tabela 1 também mostra que os acidentes com menor ocorrência (menos de 1\%) foram aqueles que envolveram Motoneta, Reboque, Trator, Veículo de Tração Animal e Triciclo. Destaca-se que apesar de um percentual aparentemente pequeno (5\%) neste ano, foram 94 acidentes que envolveram 98 ônibus. Atentando-se que se trata de um veículo de transporte coletivo de passageiros, o risco que um acidente com este tipo de veículo representa à vida e à saúde é bastante importante. Esclarece-se que a soma apresentada do percentual de acidentes supera os $100 \%$ pelo fato de que um mesmo acidente poder envolver mais de um veículo com classificações iguais ou diferentes. Analisando ainda o tipo de veículo envolvido no acidente, observa-se que muitos dos acidentes podem ter relação com o trabalho, visto que em se tratando de veículos tais como caminhões, tratores, cavalos-mecânico, ônibus, reboques e semi-reboques, há muito provavelmente a presença de um trabalhador como condutor, independente de sua relação com o mercado de trabalho.

Foi comum o acidente de trânsito que teve pelo menos um veículo envolvido com o estado dos pneus classificado na categoria "bom" (Tabela 2), e 1.658 acidentes (73,5\%) envolveram veículos com pneus classificados desta forma. Esse resultado era esperado, já que a legislação de trânsito prevê multa para veículos que circulam com pneus em estado de conservação precário. No entanto, pode ser que haja também uma relação entre "estado dos pneus" e excesso de confiança do motorista, uma vez que possivelmente um pneu em bom estado possa levar o condutor a, por exemplo, confiar mais no freio (e, portanto, abusar da velocidade) em razão da maior aderência dos pneus.

Ainda de acordo com o apresentado na Tabela 2, considerando o tempo de habilitação de pelo menos um dos motoristas envolvidos no acidente, verifica-se que a maioria dos acidentes envolveu pelo menos um condutor com tempo de habilitação entre 5 e 9 anos. Isso pode ter relação com a idade do condutor porque a idade mínima 
Tabela 1

Número e percentual de acidentes ocorridos na BR 163 segundo tipo de veículo envolvido. Mato Grosso, Brasil, 2004.

\begin{tabular}{lccc}
\hline Tipo de veículo & Número de acidentes & \% de acidentes * & Número de veículos envolvidos \\
\hline Cavalo mecânico ** & 942 & 50,08 & 1.239 \\
Automóvel & 556 & 29,56 & 614 \\
Caminhão & 484 & 25,73 & 524 \\
Caminhonete & 325 & 17,28 & 345 \\
Outros & 224 & 11,91 & 227 \\
Motocicleta & 125 & 6,65 & 137 \\
Ônibus & 94 & 5,00 & 98 \\
Camioneta & 56 & 2,98 & 58 \\
Microônibus & 30 & 1,59 & 30 \\
Bicicleta & 27 & 1,44 & 27 \\
Motoneta & 6 & 0,32 & 6 \\
Semi-reboque & 4 & 0,21 & 6 \\
Reboque & 3 & 0,16 & 3 \\
Trator & 2 & 0,11 & 2 \\
Tração animal & 1 & 0,05 & 1 \\
Triciclo & 0 & 0,00 & 0 \\
\hline
\end{tabular}

Fonte: Superintendência Regional de Polícia Rodoviária Federal de Mato Grosso, Brasil.

* O percentual de acidentes somado supera 100\% porque um mesmo acidente pode envolver 1 ou mais veículos;

** Veículo de carga não engatado ao reboque ou semi-reboque.

Tabela 2

Número e percentual de acidentes ocorridos na BR 163 segundo estado dos pneus de pelo menos um dos veículos envolvidos, tempo de habilitação do motorista e a classificação do acidente. Mato Grosso, Brasil, 2004.

\begin{tabular}{|c|c|c|c|c|c|c|}
\hline & \multicolumn{4}{|c|}{ Classificação do acidente } & \multicolumn{2}{|c|}{ Total } \\
\hline & \multicolumn{2}{|c|}{ Com vítimas } & \multicolumn{2}{|c|}{ Sem vítimas } & \multirow[b]{2}{*}{$\mathbf{n}$} & \multirow[b]{2}{*}{$\%$} \\
\hline & $\mathrm{n}$ & $\%$ & $\mathbf{n}$ & $\%$ & & \\
\hline \multicolumn{7}{|l|}{ Estado dos pneus * } \\
\hline Pneu bom & 489 & 29,5 & 1.169 & 70,5 & 1.658 & 100,0 \\
\hline Pneu regular & 93 & 37,8 & 153 & 62,2 & 246 & 100,0 \\
\hline Pneu liso & 10 & 37,0 & 17 & 63,0 & 27 & 100,0 \\
\hline Pneu ignorado & 97 & 29,8 & 226 & 70,2 & 325 & 100,0 \\
\hline Total & 688 & 30,5 & 1.568 & 69,5 & 2.256 & 100,0 \\
\hline \multicolumn{7}{|c|}{ Tempo de habilitação do motorista ** (anos) } \\
\hline Menos de 1 & 20 & 58,8 & 14 & 41,2 & 34 & 100,0 \\
\hline $1-4$ & 108 & 37,5 & 180 & 62,5 & 288 & 100,0 \\
\hline $5-9$ & 160 & 26,6 & 442 & 73,4 & 602 & 100,0 \\
\hline $10-14$ & 120 & 26,1 & 339 & 73,9 & 459 & 100,0 \\
\hline $15-19$ & 111 & 28,0 & 286 & 72,0 & 397 & 100,0 \\
\hline $20-24$ & 76 & 19,6 & 218 & 56,3 & 387 & 100,0 \\
\hline $25-29$ & 55 & 23,2 & 182 & 76,8 & 237 & 100,0 \\
\hline Mais de 29 & 26 & 66,6 & 13 & 33,3 & 39 & 100,0 \\
\hline Inabilitado & 124 & 36,3 & 218 & 63,7 & 342 & 100,0 \\
\hline Ignorado & 22 & 84,6 & 4 & 15,4 & 26 & 100,0 \\
\hline Total & 941 & 30,3 & 2.164 & 69,7 & 3.105 & 100,0 \\
\hline
\end{tabular}

Fonte: Dados da Superintendência Regional de Polícia Rodoviária Federal de Mato Grosso.

* Um mesmo acidente pode envolver mais de um veículo com estado dos pneus iguais ou diferentes entre si;

** Um mesmo acidente pode envolver um ou mais condutores com tempos de habilitação iguais ou diferentes. 
de habilitação é 18 anos e, acrescentando mais 5 a 9 anos do tempo de habilitação, teríamos então condutores com idade entre 23 a 27 anos, ou seja, os jovens e adultos jovens, concordando com a literatura que aponta ser essa a população mais atingida por esses acidentes. Pode-se também aliar a isso uma possível falta de experiência nas estradas.

Entretanto, observando a distribuição segundo a gravidade do acidente tem-se que o percentual de acidente com maior gravidade foi superior quando envolveu pelo menos um veículo com estado do pneu classificado como regular $(37,8 \%)$ ou liso (37\%). Da mesma forma, os acidentes que envolveram pelo menos um motorista com menos de um ano de habilitação, foram em sua maioria $(58,8 \%)$ classificados como 'com vítimas' (maior gravidade), bem como naqueles que envolvem motoristas que tem mais de 29 anos de habilitação (66,6\%). Deste modo, os dois extremos, de um lado o envolvimento de pelo menos um motorista pouco experiente e de outro aqueles com mais de 29 anos de experiência colaboraram na maior freqüência dos acidentes mais graves ocorridos na BR 163 no ano de 2004.

Quanto ao tipo de carga, a maior parte $(32,7 \%)$ dos veículos envolvidos em acidentes na BR 163 no ano de 2004 foi do tipo "sem carga" (caminhões descarregados e/ou cavalo mecânico). Em seguida compareceram às estatísticas a categoria "não aplicável" (24,7\%), que é em sua grande maioria composta por veículos do tipo automóveis. Quando o veículo possui carga, o tipo de carga mais comumente envolvida em acidentes é a alimentícia $(14,7 \%)$. Embora aparentemente pouco expressivo, 1,9\% dos veículos envolvidos em acidentes é veículo destinado ao transporte de produtos perigosos, somando 63 veículos envolvidos. Trata-se de um número preocupante tendo em conta a gravidade deste tipo de acidente. Um acidente envolvendo veículos com transporte de cargas perigosas pode trazer conseqüências catastróficas para o meio ambiente e saúde humana caso haja derramamento do produto transportado já que são de substâncias em geral inflamáveis e/ou tóxicas.

Considerando que muitas aglomerações se desenvolveram às margens das estradas, influenciadas pelo movimento das rodovias, o risco do acidente é muito importante para essas populações, e não somente para elas, pois podem ser acompanhadas por conseqüências calamitosas para o ambiente 7 . Além disso, uma vez contaminando o ambiente, é possível estender os efeitos deletérios a toda uma população adstrita 11
Fatores associados à gravidade dos acidentes de trânsito ocorridos na BR 163 em 2004

As Tabelas que se seguem apresentarão os resultados das análises de distribuição conjunta de fatores presentes na ocorrência de acidentes de trânsito na BR 163 em 2004 e as diversas associações encontradas $(\alpha \leq 0,05)$ relacionadas à gravidade destes acidentes.

A Tabela 3 mostra que as variáveis "condição do rolamento da pista" e "classificação do acidente" são dependentes, existindo forte associação entre elas conforme o valor de $\mathrm{p}$ apresentado. A pior condição de rolamento apresentou a menor freqüência de acidentes graves, estando relacionada a uma menor chance na ocorrência destes acidentes. Acredita-se que é possível que a condição do rolamento ruim leve o motorista a dirigir com maiores cuidados e em menor velocidade, o que acaba por reduzir a gravidade do acidente. As condições de rolamento "boa" (52\% maior), "regular" (89\% maior) e "má" (74\% maior) estiveram associadas à maior chance de ocorrência de acidentes com vítimas (com significância estatística), destacando-se a condição de rolamento regular. As condições de rolamento da pista "regular" e "má" se apresentam como situações "intermediárias", particularmente a situação "regular". É nessas condições em que se agregam a existência de situações adversas (em maior ou menor intensidade, tais como buracos, imperfeições na pista etc.) e a situação do rolamento não tão precária (como na categoria "ruim") a ponto de evitar abusos como desrespeito à sinalização, velocidade excessiva entre outros. Por conseguinte, é possível que fique mais fácil um condutor se surpreender com uma situação adversa que leve à ocorrência de um acidente mais grave. Por outro lado, a condição do rolamento "boa" é aquela que supostamente gera no condutor maior confiança, o que favorece o desenvolvimento de maior velocidade (especialmente condutores que querem recuperar o tempo perdido em trechos ruins) e ultrapassagem indevida, fatores que contribuem para a ocorrência de acidentes graves (conforme demonstrado na Tabela 4) e que podem ocasionar acidentes do tipo colisão frontal (também associadas à maior chance de acidentes graves, conforme apresentado na Tabela 5).

A Tabela 4 mostra que as variáveis "tipo de acidente" e "classificação do acidente" são dependentes, existindo forte associação entre elas conforme o valor de $\mathrm{p}$ apresentado. Tendo por base a classificação do acidente, observa-se que os acidentes derivados de colisão lateral (71\% maior), saída de pista (81\% maior), capotamento (237\% maior), colisão transversal (285\% maior), 
Distribuição conjunta dos acidentes ocorridos na BR 163 segundo condição do rolamento da pista e classificação do acidente. Mato Grosso, Brasil, 2004

\begin{tabular}{|c|c|c|c|c|c|c|c|c|c|}
\hline \multirow{3}{*}{$\begin{array}{l}\text { Condição do } \\
\text { rolamento } \\
\text { da pista }\end{array}$} & \multicolumn{4}{|c|}{ Classificação do acidente } & \multicolumn{2}{|c|}{ Total } & \multirow[t]{3}{*}{ OR } & \multirow[t]{3}{*}{ IC } & \multirow[t]{3}{*}{ Valor de $p$} \\
\hline & \multicolumn{2}{|c|}{ Com vítimas } & \multicolumn{2}{|c|}{ Sem vítimas } & \multirow[b]{2}{*}{$\mathrm{n}$} & \multirow[b]{2}{*}{$\%$} & & & \\
\hline & $\mathbf{n}$ & $\%$ & $\mathbf{n}$ & $\%$ & & & & & \\
\hline Ruim & 108 & 23,5 & 351 & 76,5 & 459 & 100,0 & 1,00 & - & - \\
\hline Má & 30 & 34,9 & 56 & 65,1 & 86 & 100,0 & 1,74 & $1,18-1,94$ & 0,028 \\
\hline Regular & 75 & 36,8 & 129 & 63,2 & 204 & 100,0 & 1,89 & $1,32-2,70$ & $<0,001$ \\
\hline Boa & 360 & 31,8 & 772 & 68,2 & 1132 & 100,0 & 1,52 & $1,06-2,85$ & 0,001 \\
\hline Total & 573 & 30,5 & 1.308 & 69,5 & 1.881 & 100,0 & & & \\
\hline
\end{tabular}

Fonte: Dados da Superintendência Regional de Polícia Rodoviária Federal de Mato Grosso.

Nota: $O$ valor do qui-quadrado calculado é significante $\left(\chi^{2}=15,99\right)$ com 3 graus de liberdade, considerando um nível de significância $\alpha \leq 0,05$.

Distribuição conjunta dos acidentes ocorridos na BR 163 segundo tipo do acidente e classificação do acidente. Mato Grosso, Brasil, 2004.

\begin{tabular}{|c|c|c|c|c|c|c|c|c|c|}
\hline \multirow[t]{3}{*}{ Tipo do acidente } & \multicolumn{4}{|c|}{ Classificação do acidente } & \multicolumn{2}{|c|}{ Total } & \multirow[t]{3}{*}{ OR } & \multirow[t]{3}{*}{ IC } & \multirow[t]{3}{*}{ Valor de $p$} \\
\hline & \multicolumn{2}{|c|}{ Com vítimas } & \multicolumn{2}{|c|}{ Sem vítimas } & \multirow[b]{2}{*}{$\mathrm{n}$} & \multirow[b]{2}{*}{$\%$} & & & \\
\hline & n & $\%$ & $\mathbf{n}$ & $\%$ & & & & & \\
\hline Colisão traseira & 79 & 18,2 & 355 & 81,8 & 434 & 100,0 & 1,00 & - & - \\
\hline Atropelamento de animal & 2 & 7,2 & 26 & 92,8 & 28 & 100,0 & 0,35 & $0,08-1,49$ & 0,153 \\
\hline Outros & 26 & 21,8 & 93 & 78,2 & 119 & 100,0 & 1,26 & $0,76-2,07$ & 0,370 \\
\hline Colisão lateral & 98 & 27,6 & 257 & 72,4 & 355 & 100,0 & 1,71 & $1,22-2,40$ & 0,002 \\
\hline Saída de pista & 142 & 28,7 & 353 & 71,3 & 495 & 100,0 & 1,81 & $1,32-2,47$ & $<0,001$ \\
\hline Tombamento & 38 & 29,0 & 93 & 71,0 & 131 & 100,0 & 1,84 & $1,17-2,88$ & 0,008 \\
\hline Engavetamento & 4 & 33,3 & 8 & 66,7 & 12 & 100,0 & 2,25 & $0,66-7,65$ & 0,195 \\
\hline Colisão com objeto fixo & 16 & 34,8 & 30 & 65,2 & 46 & 100,0 & 2,40 & $1,25-4,61$ & 0,009 \\
\hline Capotamento & 27 & 42,9 & 36 & 57,1 & 63 & 100,0 & 3,37 & $1,93-5,87$ & $<0,001$ \\
\hline Colisão transversal & 18 & 46,2 & 21 & 53,8 & 39 & 100,0 & 3,85 & $1,96-7,57$ & $<0,001$ \\
\hline Colisão frontal & 107 & 75,9 & 34 & 24,1 & 141 & 100,0 & 14,14 & $8,96-22,32$ & $<0,001$ \\
\hline Atropelamento de pedestre & 16 & 88,9 & 2 & 11,1 & 18 & 100,0 & 35,95 & $8,10-159,52$ & $<0,001$ \\
\hline Total & 573 & 30,5 & 1.308 & 69,5 & 1.881 & 100,0 & & & \\
\hline
\end{tabular}

Fonte: Dados da Superintendência Regional de Polícia Rodoviária Federal de Mato Grosso.

Nota: $O$ valor do qui-quadrado calculado é significante $\left(\chi^{2}=220,29\right)$ com 11 graus de liberdade, considerando um nível de significância $\alpha \leq 0,05$.

colisão frontal (1.314\% maior) e atropelamento de pedestre $(3.495 \%$ maior) apresentaram maiores chances de ser acidentes mais graves (com vítimas), todos com significância estatística, quando comparados com os acidentes do tipo colisão traseira. Merecem destaque os acidentes do tipo "colisão frontal" e "atropelamento de pedestre", os quais, apesar da amplitude dos intervalos de confiança, tiveram as razões de chance para a gravidade do acidente muito maiores (14 e 35 vezes, respectivamente) quando comparados com o acidente do tipo colisão traseira, que obteve uma das menores freqüências de acidentes clas- sificados como "com vítimas". Acredita-se que a colisão frontal e o atropelamento de pedestre se configuram na maioria das vezes como acidentes de maior gravidade (com vítimas), dado que o pedestre normalmente sai com algum tipo de lesão. Além disso, o choque frontal (que configura forças (velocidade) em sentido contrário) traz maior magnitude ao impacto, o que aumenta a possibilidade de causar lesões ou ferimentos nos ocupantes dos veículos.

$\mathrm{O}$ atropelamento de pedestre também se configurou como um fator de risco importante para a ocorrência de acidentes fatais no trânsito da 
Distribuição conjunta dos acidentes ocorridos na BR 163. Mato Grosso, Brasil, no ano de 2004, segundo fator contribuinte e classificação do acidente.

\begin{tabular}{|c|c|c|c|c|c|c|c|c|c|}
\hline \multirow[t]{3}{*}{ Fator contribuinte } & \multicolumn{4}{|c|}{ Classificação do acidente } & \multicolumn{2}{|c|}{ Total } & \multirow[t]{3}{*}{ OR } & \multirow[t]{3}{*}{ IC } & \multirow{3}{*}{$\begin{array}{l}\text { Valor } \\
\text { de } p\end{array}$} \\
\hline & \multicolumn{2}{|c|}{ Com vítimas } & \multicolumn{2}{|c|}{ Sem vítimas } & \multirow[b]{2}{*}{$\mathbf{n}$} & \multirow[b]{2}{*}{$\%$} & & & \\
\hline & n & $\%$ & $\mathrm{n}$ & $\%$ & & & & & \\
\hline Não manter distância de segmento & 17 & 11,3 & 133 & 88,7 & 150 & 8,0 & 1,00 & - & - \\
\hline Defeito mecânico & 24 & 19,7 & 98 & 80,3 & 122 & 6,5 & 1,92 & $0,98-3,76$ & 0,059 \\
\hline Buraco na pista & 60 & 24,3 & 187 & 75,7 & 247 & 13,1 & 2,51 & $1,40-4,50$ & 0,002 \\
\hline Dormindo & 9 & 28,1 & 23 & 71,9 & 32 & 1,7 & 3,06 & $1,22-7,69$ & 0,017 \\
\hline Ultrapassagem indevida & 42 & 28,8 & 104 & 71,2 & 146 & 7,8 & 3,16 & $1,70-5,87$ & $<0,001$ \\
\hline Falta de atenção & 95 & 30,8 & 213 & 69,2 & 308 & 16,4 & 3,49 & $1,99-6,11$ & $<0,001$ \\
\hline Velocidade incompatível & 9 & 34,6 & 17 & 65,4 & 26 & 1,4 & 4,14 & $1,60-10,74$ & 0,003 \\
\hline Defeito na via & 15 & 35,7 & 27 & 64,3 & 42 & 2,2 & 4,35 & $1,94-9,75$ & $<0,001$ \\
\hline Outras causas & 294 & 37,3 & 495 & 62,7 & 789 & 41,9 & 4,65 & $2,75-7,86$ & $<0,001$ \\
\hline Desobediência à sinalização & 8 & 42,1 & 11 & 57,9 & 19 & 1,0 & 5,69 & $2,01-16,12$ & 0,001 \\
\hline Total & 573 & 30,5 & 1.308 & 69,5 & 1881 & 100,0 & & & \\
\hline
\end{tabular}

Fonte: Dados da Superintendência Regional de Polícia Rodoviária Federal de Mato Grosso.

Nota: $O$ valor do qui-quadrado calculado é significante $\left(\chi^{2}=56,56\right)$ com 9 graus de liberdade, considerando um nível de significância $\alpha \leq 0,05$.

cidade de Marabá, Pará, em estudo realizado no período de janeiro de 2003 a dezembro de 2004 . O estudo demonstrou que a maioria dos acidentes fatais de trânsito foi proveniente de atropelamento, tendo três vezes mais chances de levar a óbito em relação a outros tipos de acidentes. Neste estudo também se constatou que os acidentes ocorridos nas rodovias (BR e PA) tiveram duas vezes mais chances de serem fatais do que os ocorridos em vias municipais, independentemente do horário em que acontecessem ${ }^{12}$. Além disso, é preciso considerar o tamanho do veículo envolvido no acidente porque a velocidade e a força do impacto que têm relação com a massa do veículo podem interferir na gravidade do acidente. Em estudo realizado em Londrina no primeiro semestre de 1996, evidenciaram-se maiores taxas de óbitos entre pessoas traumatizadas em confrontos com veículos pesados (caminhão ou ônibus) para pedestres atropelados e ciclistas que colidiram com esses veículos 13 .

Os dados apresentados na Tabela 5 mostram que as variáveis "fator contribuinte" e "classificação do acidente" são dependentes, existindo forte associação entre elas conforme p-valor apresentado. Considerando os fatores que contribuíram para a ocorrência do acidente, observa-se que em 789 acidentes (aproximadamente $42 \%$ do total) o fator contribuinte foi incluído na categoria "outras causas", o que remete ao mau preenchimento ou inadequação das categorias listadas. Dentre os fatores especificados, aqueles que contribuíram com maior chance para a ocorrência de acidentes com vítimas (com significância estatística) foram buraco na pista (151\% maior), dormindo (206\% maior), ultrapassagem indevida (216\% maior), falta de atenção ( $249 \%$ maior), velocidade incompatível (314\% maior), defeito na via (335\% maior), desobediência à sinalização (469\% maior). Em estudo sobre comportamentos de risco para acidentes de trânsito entre estudantes, também foram evidenciados como fatores contribuintes percebidos para a ocorrência ou gravidade do acidente, a falta de atenção $(59,3 \%)$, desrespeito à sinalização ou preferencial (33,5\%) e excesso de velocidade (22,5\%) 4 .

Os fatores contribuintes do tipo "não manter distância de segmento" e "defeito mecânico" foram os menos freqüentemente apontados como geradores de acidentes classificados como "com vítimas”, (11,3\% e 19,7\%, respectivamente) na BR 163 em 2004.

\section{Conclusões}

Os acidentes de trânsito, mesmo que se configurem como eventos não intencionais, são permeados por diversos fatores que muitas vezes condicionam sua ocorrência e sua gravidade. A complexidade dos fatores associados à ocorrência de acidentes de trânsito reside no fato de se referirem a um conjunto de circunstâncias e fatores logísticos e ambientais ligados não somente ao condutor, mas também ao veículo, à via pública, além da estrutura da fiscalização, distribuição de movimentação de pessoas e mercadorias, entre outras, muito embora, no campo do senso 
comum, o comportamento do motorista (ações ou omissões humanas) tem sido privilegiado entre os fatores contribuintes para o acidente, sendo estes denominados de imprudência, falha humana, ou ato inseguro do condutor.

Nas próprias medidas de controle propostas para redução de acidentes são focalizadas ações no indivíduo, por serem consideradas ações eficazes, normalmente de baixo custo, com potencial de evitar o acidente ou reduzir significativamente sua gravidade. No entanto, é preciso considerar que estímulos externos, providos pelo sistema viário e seu entorno, podem contribuir para a maior ou menor segurança do trânsito e para a redução ou aumento dos acidentes tais como presença ou ausência de elementos de sinalização, os quais repassam ao condutor muitas informações necessárias, bem como as condições da pista, as quais também interferem no desempenho da tarefa de dirigir um veículo.

Assim, é preciso evidenciar que a redução do número de acidentes implica considerar outros aspectos que não apenas o condutor, mas também outros como as condições das rodovias, da sinalização e as condições de trabalho daqueles que continuamente trafegam pelas rodovias do país. Estas modificações, de ordem estrutural, muitas vezes são preteridas em detrimento de questões de ordem política, econômica ou burocrática, ficando a minimização dos acidentes à mercê da atitude individual do condutor, limitando-se a necessidade de mais investimento em educação no trânsito e aumento da fiscalização, fatores sem dúvida importantes, mas que por si só têm demonstrado que não resolvem o problema.

Neste trabalho foi possível destacar fatores contribuintes de relevo para maior gravidade dos acidentes. Existem aqueles que estão ligados à atitude do indivíduo (estar dormindo, falta de atenção, velocidade incompatível e desobediência à sinalização), mas também aqueles ligados a situação da rodovia (buraco na pista e defeito na via) os quais também estiveram associados à maior chance (estatisticamente significativa) de ocorrência de acidentes mais graves.
Uma outra questão externa associada também à gravidade do acidente foi a condição de rolamento da pista, que permitiu que se observasse, ao contrário do suposto, que a incidência dos acidentes mais graves é menos freqüente nas condições de "rolamento ruim" que nas demais condições. As condições melhores estiveram associadas à maior chance de ocorrência de acidentes. No entanto, não se pode fazer uma análise isolada e concluir que a pista com condição de rolamento ruim foi por si só um fator de proteção para a ocorrência de acidentes mais graves. Possivelmente muitos fatores podem estar confundindo este achado, por exemplo, a velocidade que se trafega numa via com condição de rolamento ruim, o excesso de atenção neste tipo de pista, entre outros. Deve-se estimular a melhoria das condições gerais das rodovias, pois desta forma alguns dos fatores presentes na ocorrência de acidentes, tais como buracos, defeitos na pista, condições inadequadas de sinalizações (horizontal e vertical) poderão ser corrigidos, o que sem dúvida irá favorecer a minimização do problema do acidente.

Supõe-se que fatores de ordem regional podem estar influenciando a dinâmica dos acidentes na rodovia BR 163, muitos dos quais precisam ser ainda investigados, sobretudo os relacionados ao escoamento da produção da área de influência desta rodovia, as características específicas da frota de automóveis que circula por ela, o fluxo de veículos, bem como outros de ordem cultural ou de fiscalização, que podem interferir no descumprimento da legislação de trânsito.

É preciso ainda ressaltar que, tendo em vista a possibilidade de pavimentação/revitalização da BR 163, espera-se um aumento importante no fluxo de veículos que transitarão por esta rodovia, mormente para realizar o transporte de produtos agrícolas até o porto de Santarém, no Estado do Pará. Este é um dos motivos que destaca a urgente necessidade de medidas de intervenção de caráter mais global na problemática dos acidentes nesta rodovia, considerando não apenas questões individuais de comportamento do condutor, mas alcançando questões regionais e suas dimensões econômicas, sociais e culturais. 


\section{Resumo}

O transporte é essencial para o desenvolvimento econômico de Mato Grosso, Brasil, sendo a BR 163 a principal rodovia de escoamento da produção agropecuária da região. Uma das conseqüências desta atividade é a ocorrência de acidentes de trânsito. Com o objetivo de analisar e categorizar os principais fatores associados à ocorrência de acidentes nesta rodovia, foram utilizados dados da Superintendência de Polícia Rodoviária Federal referentes ao ano de 2004. Nos resultados, destacaram-se como fatores associados à maior chance de ocorrência de acidentes com vítimas (com significância estatística): a condição de rolamento regular $(O R=1,89 ;$ IC: 1,32-2,70); os acidentes do tipo colisão frontal (OR = 14,14; IC: 8,96-22,32) e atropelamento de pedestre (OR =35,95; IC: 8,10-159,52); e os fatores contribuintes defeito na via $(\mathrm{OR}=4,35$; IC: $1,94-9,75)$ e desobediência à sinalização (OR = 5,69; IC: 2,01-16,12). Conclui-se que para reduzir o problema dos acidentes nesta rodovia é preciso estabelecer medidas de intervenção de caráter global, não focalizando ações somente na modificação do comportamento do condutor e na fiscalização, mas considerando questões regionais e suas dimensões econômicas, sociais e culturais.

Acidentes de Trânsito; Estradas; Veículos Automotores

\section{Referências}

1. Gonçalves F, Morita PA, Haddad S. Seqüelas invisíveis dos acidentes de trânsito: o transtorno de estresse pós-traumático como problema de saúde pública. Brasília: Instituto de Pesquisa Econômica Aplicada; 2007. (Texto para Discussão, 1291).

2. Santos S. Um estudo sobre a participação do modal ferroviário no transporte de cargas no Brasil [Dissertação de Mestrado]. Florianópolis: Universidade Federal de Santa Catarina; 2005.

3. Iunes RF. III - Impacto econômico das causas externas no Brasil: um esforço de mensuração. Rev Saúde Pública 1997; 31(4 Suppl):38-46.

4. Andrade SM, Soares DA, Braga GP, Moreira JH, Botelho FMN. Comportamentos de risco para acidentes de Trânsito: Um inquérito entre estudantes de medicina na Região Sul do Brasil. Rev Assoc Med Bras 2003; 49:439-44.

5. Sauer MTN, Wagner MB. Acidentes de trânsito fatais e sua associação com a taxa de mortalidade infantil e adolescência. Cad Saúde Pública 2003; 19:1519-26.

6. Queiroz MS, Oliveira PCP. Acidentes de trânsito: uma visão qualitativa no Município de Campinas, São Paulo, Brasil. Cad Saúde Pública 2002; 18:1179-87.

7. Ferreira CEC. Acidentes com motoristas no transporte rodoviário de produtos perigosos. São Paulo Perspect 2003; 17:68-80.

\section{Colaboradores}

L. V. C. Almeida elaborou o projeto, levantou e analisou os dados e redigiu o trabalho. M. G. Pignatti orientou a confecção do projeto e revisou o trabalho. M. M. Espinosa participou da análise estatística dos dados e da revisão do trabalho.

\section{Agradecimentos}

Os autores deste trabalho agradecem o apoio financeiro do Conselho Nacional de Desenvolvimento Científico e Tecnológico (CNPq) mediante o financiamento do Projeto de Pesquisa: O Impacto das Transformações Produtivas no Ambiente e na Saúde da População dos Municípios da Área de Influência da BR 163 (Edital MCT-CNPq/ MS-SCTIE-DECIT - no. 34/2005). Agradecem também à 2a Superintendência Regional de Polícia Rodoviária Federal do Estado de Mato Grosso pela disponibilização dos dados de acidentes.
8. Barros AJ, Amaral RL, Oliveira MS, Lima SC, Gonçalves EV. Acidentes de trânsito com vítimas: subregistro, caracterização e letalidade. Cad Saúde Pública 2003; 19:979-86.

9. Departamento Nacional de Infra-estrutura de Transportes. Condições das rodovias 11a Unidade de Infra-Estrutura Terrestre - Mato Grosso. http:// www1.dnit.gov.br/rodovias/condicoes/mt.htm (acessado em 28/Abr/2008).

10. Departamento Nacional de Estradas de Rodagem. Manual de sinalização rodoviária. http://www1. dnit.gov.br/arquivos_internet/ipr/ipr_new/ma nuais/ManualSinalizacaoRodoviaria.pdf (acessado em 11/Abr/2008).

11. Herculano S, Porto MFS, Freitas CM. Qualidade de vida e riscos ambientais. Niterói: Editora da UFF; 2000.

12. Oliveira LC. Estudo dos fatores de risco de acidentes fatais no trânsito da cidade de Marabá-Pará [Trabalho de Conclusão de Curso]. Belém: Universidade Federal do Pará; 2005. http://www.ufpa. $\mathrm{br} / \mathrm{ccen} / \mathrm{est} /$ documentacao/tcc/luiz_oliveira2004. pdf (acessado em 15/Jan/2008).

13. Andrade SM, Mello Jorge MHP. Acidentes de transporte terrestre em município da Região Sul do Brasil. Rev Saúde Pública 2001; 35:318-20.

Recebido em 31/Out/2007

Versão final reapresentada em 08/Mai/2008 Aprovado em 31/Jul/2008 